ISSN electrónico: 2172-9077

https://doi.org/10.14201/fjc2017152742

\title{
EL CINE COMO MEDIO DE COMUNICACIÓN SOCIAL. LUCES Y SOMBRAS DESDE LA PERSPECTIVA DE GÉNERO
}

\section{The Cinema as a Social Mass Media. Lights and Shadows from the Gender Perspective}

\author{
Dra. Beatriz MORALES ROMO \\ Profesora Universidad Internacional de la Rioja. España \\ E-mail: beatriz.morales@unir.net \\ (iD http://orcid.org/0000-0002-2793-7034
}

Fecha de recepción del artículo: 20/09/2017

Fecha de aceptación definitiva: 12/10/2017

\begin{abstract}
RESUMEN
El artículo versa sobre el cine como medio de comunicación social, en relación a la influencia que ejerce sobre niños y jóvenes. Partiendo de sus distintas vertientes, se profundiza en su papel como transmisor de estereotipos, con especial atención a la perspectiva de género. La metodología empleada ha sido mixta: cuantitativa y cualitativa. Por un lado, se ha aplicado una encuesta a 251 estudiantes de varias titulaciones universitarias y, por otro, se han realizado entrevistas en profundidad a expertos, y se han estudiado las 20 películas de género romántico más taquilleras de la primera década del siglo XXI a través de fichas de análisis. Los resultados obtenidos orientan sobre la repercusión del cine como medio de comunicación de masas en sus espectadores, así como su contribución a la perpetuación de estereotipos de género, a pesar de que se observa una evolución en pro de la igualdad.
\end{abstract}

Palabras clave: cine; estereotipo; género; medios de comunicación de masas; socialización.

\begin{abstract}
This article includes studies cinema as a social mass media, in relation to the influence it exerts on children and young people. From different aspects of the cinema, we deep in its role as transmitter of stereotypes, with special attention to the gender perspective. The methodology used has been both, quantitative and qualitative. On the one hand, a survey of 251 students of various university degrees has been applied and, on the other hand, in-depth interviews have been conducted with experts, and the 20 best-selling romantic films of the first decade of the 21 st century have been studied through analysis sheets. The results obtained focus on the repercussion of cinema as a mass media among its spectators, as well as its contribution to the perpetuation of gender stereotypes, despite the fact that there is an evolution towards more equality.
\end{abstract}

Key words: cinema; stereotype; gender; mass media; socialization.

\section{INTRODUCCIÓN}

Es innegable la importancia del cine como medio de comunicación audiovisual y su repercusión social en numerosos ámbitos. Se dirige primordialmente a las masas, al individuo y a la sociedad; establece un contacto directo con el espectador, con el público y, por tanto, con la sociedad del momento, de la cual también forman parte los y las cineastas. 
Benet (2004) establece un círculo completo al que denomina el Círculo de la comunicación que comienza con el Cineasta (emisor), sigue con la Película (mensaje connotado), continua con el Espectador (receptor) y la Sociedad (contexto) para terminar de nuevo en el Cineasta en una especie de feedback intercomunicado. Todos estos elementos tendrán cabida en este artículo que explora el cine desde la perspectiva de sus repercusiones sociales, con especial atención a la perspectiva de género.

A través de este poderoso medio de comunicación que es el cine, el público toma contacto intelectual con otras comunidades humanas - por virtud de la imagen fílmica- y capta, o potencialmente puede hacerlo, los problemas de ciertos hombres y mujeres contemporáneos, quizás análogos a los suyos, en los diversos estratos sociales y diferentes países; llegando en ocasiones a un conocimiento mayor de otras culturas, de otras mentalidades, a veces lejanas o poco comprensibles normalmente.

La eficacia educativa de la imagen es muy relevante, ya que está comprobado que la mente humana retiene mucho más la imagen que cualquier otro signo de comunicación. Es más efectivo, por tanto, todo aquel conocimiento intelectual que nos llega por medio de la realidad, de la praxis y no a través de la teoría. Y el cine es una interpretación seleccionada de la realidad que, además de entretener y evadir, puede ser un elemento que apuntale o deconstruya ideas, estereotipos, mitos, prejuicios, etc.

En este acercamiento al cine haremos un repaso por sus distintas vertientes para dejar constancia de sus múltiples facetas: como elemento artístico, como espectáculo e industria, como leguaje y desde la perspectiva de sus espectadores. A partir de estas premisas, se profundiza en sus funciones más allá de la evasión y el ocio, para llegar a desentrañar las relaciones que establece con el mantenimiento de estereotipos, especialmente los referidos a cuestiones de género.

\section{LAS DISTINTAS VERTIENTES DEL CINE}

Adela Kohan es un referente necesario a la hora de abordar las funciones del cine. Para ella el cine formula preguntas que permiten conectar desde nuevas perspectivas con uno mismo, una película pone en movimiento historias personales, recuerdos, necesidades, deseos, abre puertas que tal vez habrían permanecido cerradas sin esa película, puede ser una guía vital (Kohan, 2006).

Varios autores han constatado la influencia del cine en la modificación de actitudes y conductas (Sell, Martínez-Pecino y Loscertales, 2014; Gómez, 2017) mostrando especial interés en niños y jóvenes.

El cine influye en el mundo interno, ayuda a resolver conflictos, cambiar actitudes, y hábitos que limitan, desarrolla la creatividad, mejora la comunicación y también contribuye a desechar emociones negativas. Por todo ello ha sido utilizado como apoyo pedagógico en las aulas. Para Leigh (2002) promueve el desarrollo de habilidades sociales, predispone a la reflexión y el análisis crítico. Desde una perspectiva más amplia y, tratándose de una producción cultural, contribuye a la formación en valores (Blasco, et al., 2015; Escámez y Gil, 2001; González, 1996; Alonso y Pereira, 2000) y a la inteligencia ética (Jaimes, 2016).

El uso terapéutico del cine también ha sido constatado en distintos trabajos, así en aplicaciones concretas como educación familiar (Higgins y Dermer, 2001), educación médica (Tabernero, 2016; McCann y Huntley-Moore, 2016), educación ambiental (Stadler, 2017) o mejora de las relaciones de pareja (Molina, 2016; Caballo, 2014).

Estas utilidades del cine más allá del ocio no son nuevas. San Román (2010) asegura que el cine desde sus orígenes, más que una función lúdica, ha tenido una vocación didáctica y moralizante.

Sumergirse en el cine es mirarse en un espejo en el que la gente no se había mirado hasta ese momento, ver a otro al que le pasan cosas parecidas a las que le ocurren a uno (sirve también para desarrollar la empatía), que hace lo que uno podría hacer y no se atreve, nos lleva a preguntarnos sobre el sentido de la propia vida y por las decisiones tomadas. Los sentimientos se activan porque la pelícu- 
la está especialmente pensada para ello. A veces un personaje te hace llorar porque te sientes reflejado en él o porque encarna lo que más deseas (Kohan, 2006).

El cine como medio de comunicación social constituye un elemento complejo. Para su mejora comprensión y análisis, se realiza un acercamiento dentro de tres grandes apartados; tres aspectos de una misma realidad que nos hacen ver el fenómeno fílmico desde diversos ángulos: como arte, como espectáculo e industria y a través de sus espectadores.

\section{El cine como arte}

El Manifiesto de las siete artes de 1911 elevó al cine a la categoría del «séptimo arte» (Montiel, 1999). Esta denominación que atesora más un siglo lleva implícito un reconocimiento al cine y a su relevancia social. Tal como señala Ruiz (2013) en el cine confluyen el teatro, la música, la literatura, la pintura, la arquitectura y la danza, por eso fue considerado como «arte madre», ya que orquestaba distintos artes que lo precedieron.

En los años veinte, el expresionista Paul Wegener lo definiría como «el arte de las imágenes fotográficas en movimiento». De ahí que el cine quede enmarcado dentro de las concepciones que sobre las bellas artes han dado los filósofos y estéticos: desde Santayana y Splengler hasta de Santis y Lange, pasando por Gilson, Croce, Marittain u Ortega y Gasset.

Más recientemente Alain Badiou sostiene que «el cine es un arte de masas porque es arte de la imagen, y la imagen puede fascinar a todo el mundo» (2004, p. 31).

Ahora bien, el cine como arte implica un saber hacer, porque participa de la ciencia (saber) y de la técnica (hacer). Toda película narra una historia que se ha de concretar, para que sea operativa, en un guion cinematográfico. El guion es un elemento clave del arte fílmico al que se le exigen varias premisas: calidad lingüística, ingenio en el diálogo, coherencia en el razonamiento, dignidad de la expresión... Pero la película es algo más que el guion, también la fotografía y la ambientación son factores plásticos del cine. Además de la calidad técnica hay que valorar otros aspectos muy importantes: el empleo de la luz y del color según las situaciones, los estados de ánimo, los emplazamientos. Todos estos factores han de ser coherentes con el desarrollo de la narración y ayudar a que el espectador descubra lo que el guion omite. Por último, las otras dos piezas básicas de la realización cinematográfica que, desde posiciones diferentes, aunque convergentes «mueven la película»: los intérpretes y el director o realizador (Benet, 2004).

Los inventos tecnológicos han formado parte del cine desde sus inicios, si bien las nuevas tecnologías han cambiado tanto la forma de hacer cine en las últimas décadas que se considera que el cine digital es la revolución de la industria en el siglo XXI (Sabeckis, 2013).

\section{El cine como espectáculo e industria}

«El cine es asimismo un espectáculo, un ingenio curioso que atrajo la atención del espectador, público que pronto transformaría el cine en un vehículo de sus propios sueños e intelecciones y, a veces, inhibiciones, que son: evadirse de la realidad diaria, identificarse con los héroes, protagonistas, vivir la historia que se plantea en la pantalla, y por medio de esta distracción o divertimiento colectivo, la gente se aleja u olvida por unas horas de sus problemas» (Caparrós, 2007, p. 58).

A este respecto debemos hablar del concepto de industria cultural acuñado por primera vez por la Escuela de Frankfurt para reflejar el gran cambio producido tanto en la producción como en los efectos sociales de la cultura (Zallo, 1992). Sin duda un autor que se ha interesado por esta visión es el mejicano Othón Téllez, quien plantea la triada de los productos culturales en la que diferencia entre producción, distribución y consumo: «En el cine, el ritmo de un película nos puede llevar al desplaza- 
miento de ésta en el tiempo y en el espacio (...) El consumo artístico será aquel que permita reportar en el espectador la mayoría de elementos formales utilizados: composición, ritmo, color, sonido, tiempo, entre otros, con base en la disciplina en cuestión y el valor que cada uno de ellos le brinde al consumidor cultural en su formación como individuo, motivando en él múltiples interpretaciones y significaciones respecto al producto cultural consumido» (Téllez, 2005, p. 45).

Con los cambios producidos en la era global e informacional, el cine como industria ha ampliado sus fronteras al integrarse en un mercado mucho más amplio, el audiovisual, asumiendo estrechas relaciones con la televisión por cable y por satélite. Su consumo se ha extendido y ya no se restringe a las salas cinematográficas, sino que es una práctica habitual en muchos hogares. Por tanto, su potencial económico se ha diversificado al tiempo que ha ampliado considerablemente sus audiencias.

\section{El cine a través de sus espectadores}

Aunar arte y espectáculo, cultura y negocios, permite una mejor comercialización de producciones cinematográficas al ajustarse mejor a las demandas de entretenimiento de los espectadores (Lozano, et al., 2009). Es decir, el cine constituye una industria económica que pone en relación a los compradores (espectadores) con los vendedores (artistas, productores...) (McConnell, 1997).

De forma habitual se habla del cine convencional y comercial, el que solemos ver más a menudo, como un lugar de evasión y diversión. Para McKee (2011) el ritual de visionado de una película y su relación con las emociones constituye una actividad importante en la sociedad actual.

En el espectador, siguiendo a Mayne (1993), podemos apreciar tres niveles; el de persona real que acude al cine (incluyendo su dimensión psíquica), el sujeto construido teóricamente por la cultura, y entre ambos el espectador. Diferenciar estos niveles puede servir para entender mejor las interacciones que determinan la histórica del cine desde su creación a su recepción.

Tres serían los factores narrativos que generan satisfacción en los espectadores: el personaje principal, el antagonista y la tensión (Lozano, et al., 2012).

La lectura de diversos trabajos que analizan el cine nos orienta hacia la idea de que el espectador no es solo un sujeto o una colectividad de individuos enfrentados a una pantalla, sino que constituiría una institución y un componente fundamental con importantes influencias en el cine como arte y como industria.

La influencia que el cine ejerce en los espectadores ha sido objeto de análisis en diversos trabajos (Sell, et al., 2014; Mangot y Vasantmeghna, 2017) concluyendo el gran poder que el primero ejerce en los segundos.

\section{ESTEREOTIPOS Y SISTEMAS DE COMUNICACIÓN DE MASAS: PRESENCIA, FUNCIONES Y SIGNIFICADOS}

«La mejor manera de dominar los estereotipos y si se desea, desterrarlos, es estudiarlos y comprenderlos. Y los Medios son el lugar idóneo para acometer esa obra» (González Galiana, 1999, p. 26).

El actual sistema de comunicación de masas presenta una fuerte tendencia a dar prioridad a los contenidos de evasión y a los productos de ficción. Estos constituyen una verdadera área expresiva que se articula en varios tipos de mensajes que -aun siendo muy diferentes entre sí-, por los contenidos y por el tipo de público al que se dirigen, parecen desarrollar una función y adquirir un significado muy similar. Al mismo tiempo, nos encontramos frente a un área muy mediatizada cada vez más vinculada a la televisión, pero también al espectro editorial, al periodístico (desde las crónicas de sociedad a las telenovelas) y, cómo no, al cine. Todos estos medios de comunicación tienen en común que 
facilitan las reflexiones sobre los estereotipos, pues muestran y difunden lugares comunes socialmente aceptados y patrones que se consideran invariables.

El cine, junto con otros medios de comunicación de evasión y debido a su carácter de objeto y ocasión de intercambio con el grupo de iguales, son parte integrante del proceso de formación de una primera identidad colectiva con gran poder socializador. Son numerosos los trabajos que se interesan por las relaciones entre cine y socialización (Ojeda, 2016; Castro, 2006) y, dentro de ellos, los que analizan las producciones cinematográficas infantiles en este sentido (Martínez y Merlino, 2006; Porto Pedrosa, 2010). Parece probado que los niños y niñas aprenden desde edades muy tempranas a reconocerse en los otros, y este proceso está muy condicionado por los temas y contenidos que la ficción les muestra.

«Lo que somos y lo que creemos ser, lo que vemos y creemos ver se deduce de los medios. El consenso se establece allí, donde todos confluimos» (Gutiérrez, 2007, p. 67). En esta misma línea Almacellas (2004) apunta a que las obras cinematográficas constituyen un espacio donde los espectadores pueden repensar y reflexionar sobre su propia vida, contribuyendo a la construcción de identidades individuales y colectivas. Por tanto, el cine puede contribuir a crear y construir imágenes que sean igualitarias, sexistas, racistas, clasistas o por el contrario diluir estereotipos e ideas preconcebidas que vienen lastrando las relaciones humanas. En este sentido, el cine puede contribuir desde la perspectiva de género, a ofrecer imágenes de relaciones de pareja igualitarias que se separen de viejas losas patriarcales y machistas. Charkow y Nelson (2000) apuntaron que el cine dentro del proceso socializador, al igual que ocurre en la vida cotidiana, atesora unos valores imperantes ligados al sistema patriarcal.

«Si a lo largo de la historia ha pervivido el sexismo en el lenguaje ha sido porque la sociedad no ha demandado su cambio. En nuestra cultura instituciones poderosas como la Iglesia Católica, han favorecido el mantenimiento de manifestaciones sexistas en el lenguaje, basadas en una larga trayectoria de carácter patriarcal» (López, 2008, p. 37).

La literatura científica suele considerar a los estereotipos como un elemento con claras connotaciones negativas, aunque también hay ejemplos que constatan que algunos estereotipos tienen también sus oportunidades de uso y, por tanto, su razón de ser, como por ejemplo el lenguaje burocrático; un conjunto de frases estereotipadas que, precisamente por ello, permiten un rápido y fácil aprendizaje y pueden ser utilizadas incluso por personas de escasa competencia lingüística (Morales, 2015).

Tal como señala Puleo (2005), los medios de comunicación incitan a la desigualdad de género en la vida real a través de las imágenes, estereotipos y mitos que transmiten, contribuyendo al mantenimiento de un patriarcado «de consentimiento». En la misma línea, Caparrós (2007) sostiene que los medios de comunicación de masas tienden a mostrar las situaciones sociales más estereotipadas, perpetuándolas e incluso acrecentándolas.

\section{MetodologíA}

\section{Objetivo}

Este trabajo indaga sobre el cine como medio de comunicación desde una perspectiva social, es decir, interesándose por sus repercusiones y contribuciones sociales. Persigue responder a todos objetivos de investigación: determinar si el cine romántico proyecta una imagen de las relaciones de pareja conservadora o igualitaria y, por otra parte, analizar las influencias que produce en sus espectadores.

Para ello analiza aspectos intrínsecos (como la influencia de productoras u otros aspectos empresariales) y extrínsecos (sus influencias en los espectadores, manipulación de percepciones, etc.), tratando de determinar su alcance en relación a los estereotipos de género: si los perpetúa o si contribuye a diluirlos. 


\section{Diseño de investigación}

Se trata de un diseño no experimental apoyado en una metodología mixta, tanto cuantitativa (encuesta) como cualitativa (entrevistas personales y análisis fílmico de las películas seleccionadas).

Se realizaron de forma independiente cada una de las tres metodologías. Se comenzó por validar el cuestionario con 4 expertos en la materia en relación al contenido y formulación. Una vez validados y realizados los cambios sugeridos, se aplicó en las distintas Universidades.

A continuación, se realizó la selección de expertos para aplicar las entrevistas semiestructuradas.

Paralelamente se realizó la selección de las 20 películas románticas más taquilleras de la primera década del siglo XXI y se comenzó con su análisis.

\section{Muestra}

La muestra del estudio está compuesta por 251 estudiantes de titulaciones universitarias vinculadas al ámbito de la Educación (Magisterio y Pedagogía) y al de la Comunicación (Publicidad y Relaciones Públicas) de las ciudades de Salamanca y Ávila. Los gráficos 1 y 2 informan su composición. El primero refleja una clara predominancia del sexo femenino respecto del masculino, por lo que se trabajará con los datos relativos, esto es, con porcentajes en lugar de con valores absolutos, aunque ambos se mostrarán en las tablas de contingencia. El gráfico 2 refleja la aportación de distintas titulaciones a la muestra.

Gráfico 1. Sexo de los encuestados

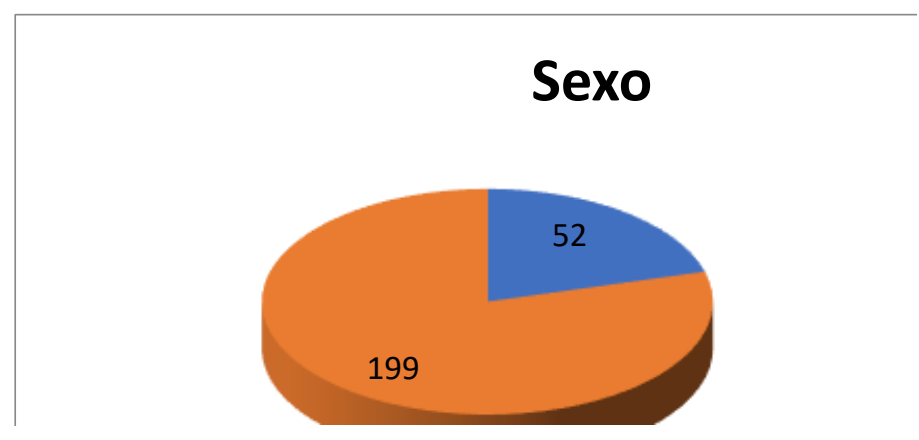

Gráfico 2. Titulación de los universitarios encuestados

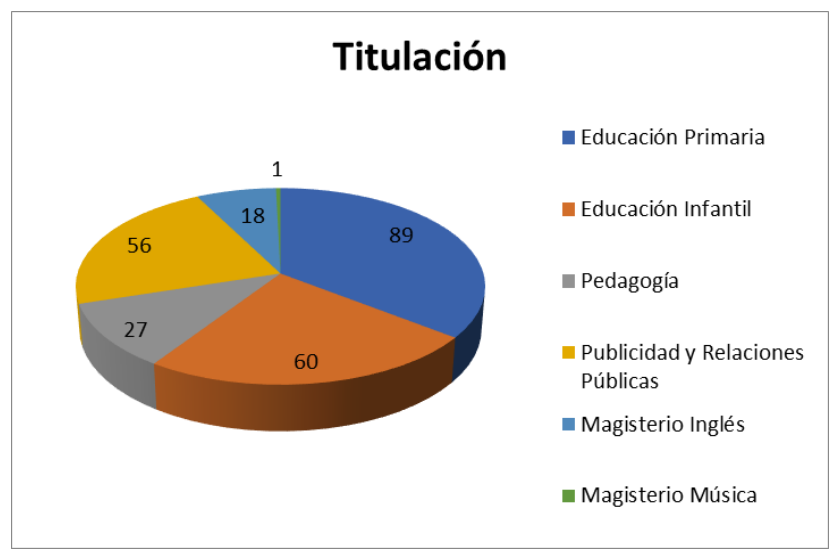


Se ha realizado un muestreo no probabilístico por conveniencia por su facilidad operativa y bajos costes. Para ello se contactó con distintos profesores de las titulaciones seleccionadas para aplicar la encuesta dentro de sus clases.

En la investigación cualitativa, se han llevado a cabo 6 entrevistas personales a diversos profesionales del campo de la educación, comunicación, expertos en género e igualdad que han sido seleccionados por ser sujetos portadores de significados en el tema objeto de estudio.

Los profesionales seleccionados responden a los siguientes perfiles:

E1: Profesora titular de Comunicación Audiovisual de universidad española, 52 años.

E2: Profesor titular del área de Filología en universidad española, 45 años.

E3: Profesora Catedrática del Master de Estudios Interdisciplinares de Género., 59 años.

E4: Profesor Contratado Doctor del área de Comunicación de facultad española, 47 años.

E5: Licenciada en Ciencias de la Educación Física y del Deporte y alumna del doctorado de Estudios Interdisciplinares de Género en universidad española, 28 años.

E6: Profesor del Master de Estudios Interdisciplinares de Género. 36 años.

En cuanto a las películas, los 20 films más taquilleros de género romántico producidos en la primera década del S. XXI fueron: Mi gran boda griega; ¿En qué piensan las mujeres?; Hitch especialista en ligues; Los padres de ella; Sexo en Nueva York Iy II; American Pie 2; Como la vida misma; El diablo se viste de Prada; 50 primeras citas; Historias de San Valentín; Todo incluido; Cómo perder a un chico en 10 dias; ¿Qué les pasa a los hombres?; Espera al último baile; La cruda realidad; El diario de Noa; Querido John; Chocolat y Cartas para Julieta.

\section{Análisis de datos}

Dentro de esta investigación interpretativa e inferencial, se han seguido una serie de fases para extraer los datos.

1. Análisis individual de los datos procedentes de los tres métodos de investigación empleados, esto es: encuesta a alumnado universitario, entrevistas a expertos y análisis de películas de género romántico.

Encuesta: dentro del acercamiento cuantitativo, se ha realizado un análisis descriptivocorrelacional con el programa estadístico SPSS 24.0.

Entrevistas: tras su transcripción íntegra, se procedió a la codificación de la información agrupándola en distintas categorías correspondientes a los objetivos planteados. Se extrajeron, dentro de cada categoría, los verbatim más representantivos.

Películas: para su análisis se ha empleado una ficha analítica que estudia las relaciones de pareja mostradas en cada film. Se parte de dos modelos: el Tradicional apoyado en estereotipos de género, desigualitario y sexista, con una serie de variables con una connotación negativa, y el Alternativo, basado en relaciones de igualdad entre los dos miembros de pareja, amistad, respeto y consideración para ambos. La aplicación de estas fichas de relación de pareja a cada película pretende identificar si sus relaciones se ajustan más a uno u otro modelo a partir de la verificación de la existencia de las distintas variables en la muestra de películas seleccionada. 
Tabla 1. Ficha de análisis de las relaciones de pareja

\begin{tabular}{|l|l|}
\hline \multicolumn{2}{|c|}{ MODELO TRADICIONAL } \\
\hline Sumisión & Manipulación / engaño \\
\hline Dependencia & Inevitabilidad \\
\hline Violencia & Amor-sufrimiento \\
\hline Maltrato & Celos \\
\hline Ocultación / infidelidad & Rechazo / miedo \\
\hline \multicolumn{2}{|c|}{ MODELO ALTERNATIVO } \\
\hline Amistad & Fidelidad \\
\hline Igualdad & Ternura \\
\hline Amor & Transparencia \\
\hline Independencia & Compartir \\
\hline Respeto & Diálogo entre iguales \\
\hline
\end{tabular}

Fuente: elaboración propia.

2. Triangulación de los datos. Más concretamente se ha empleado la triangulación de métodos (el «arquetipo de triangulación») y, dentro de esta la variación intermétodos que mide el grado de validez externa de los datos.

Figura 1. Esquema de triangulación

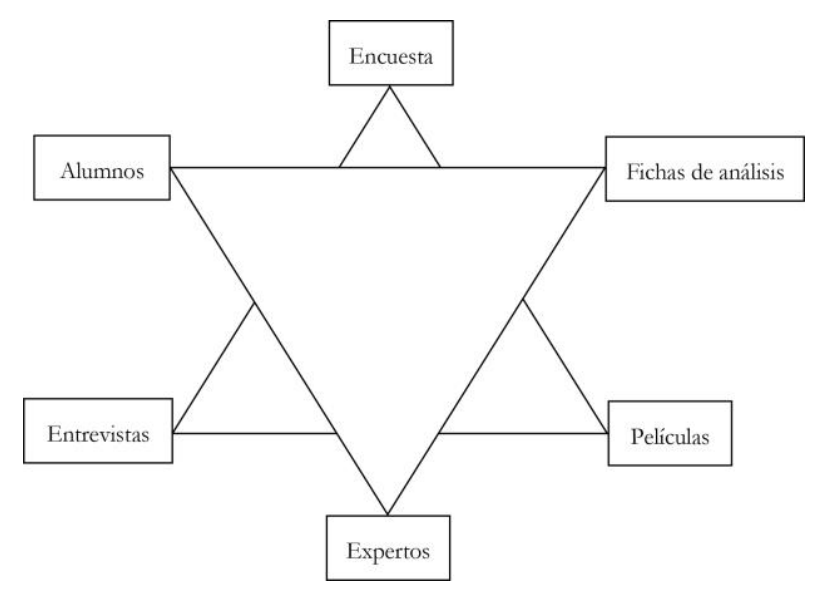

\section{RESULTADOS}

Fuente: elaboración propia.

La investigación arroja una serie de datos que serán expuestos en torno a los dos núcleos temáticos: el cine como medio de comunicación social y su influencia en la educación de niños y jóvenes.

\section{El cine como medio de comunicación social}

Tanto las entrevistas como los cuestionarios se han referido al cine como un medio de comunicación con múltiples aristas, influencias y significados. Los expertos han sido muy recurrentes a la hora de vincular el cine con la sociedad y con su reflejo de una imagen ligada a la realidad social que se vive en cada momento. No obstante, parece que su evolución no es lineal. 
La opinión de casi la mitad de los estudiantes encuestados es que el cine supone una evasión de la realidad «muchas veces», y para casi el $40 \%$ lo consigue «algunas veces». Los hombres consideran al cine como un medio de comunicación que sirve para una evasión de la realidad en un mayor porcentaje que las mujeres, $56 \%$ frente al 44,7\%. A pesar de las diferencias porcentuales entre hombres y mujeres, la variable sexo no resulta estadísticamente significativa.

Tabla 2. El cine como evasión de la realidad

\begin{tabular}{|l|l|l|r|r|r|r|r|}
\hline \multicolumn{2}{|l|}{} & Nunca & Algunas veces & Muchas veces & Siempre & Total \\
\hline $\mathrm{S}$ & \multirow{2}{|l|}{$\mathrm{H}$} & Valor absoluto & 1 & 14 & 28 & 7 & 50 \\
\cline { 2 - 8 } $\mathrm{X}$ & $\%$ & $2,0 \%$ & $28,0 \%$ & $56,0 \%$ & $14,0 \%$ & $100,0 \%$ \\
\cline { 2 - 8 } $\mathrm{O}$ & $\mathrm{M}$ & Valor absoluto & 5 & 81 & 88 & 23 & 197 \\
\cline { 2 - 8 } & $\%$ & $2,5 \%$ & $41,1 \%$ & $44,7 \%$ & $11,7 \%$ & $100,0 \%$ \\
\hline \multirow{2}{*}{ Total } & Valor absoluto & 6 & 95 & 116 & 30 & 247 \\
\cline { 2 - 8 } & $\%$ & $2,4 \%$ & $38,5 \%$ & $47,0 \%$ & $12,1 \%$ & $100,0 \%$ \\
\hline
\end{tabular}

Para los estudiantes varones el cine refleja una realidad social más sesgada que para sus homólogas femeninas, sorprendiendo el $16 \%$ de los que piensan que esto ocurre siempre, frente a un 1,5\% de las mujeres. La respuesta mayoritaria para ambos sexos es que el cine ofrece reflejos sesgados algunas veces, pero son ellos los que aprecian más sesgos.

En la última pregunta del cuestionario (abierta), se solicitaron comentarios sobre las imágenes de mujeres y hombres y de las relaciones de pareja en el cine romántico. La tónica general fue la misma. Recogemos cinco de las respuestas que mantienen el reflejo poco real de las películas románticas.

Amor demasiado surrealista. C2

En las películas lo ponen todo muy bonito, pero está muy lejos de la realidad. C6.

Generalmente se muestra a un hombre sumiso que se deja manipular por la mujer. A esta se la califica de caprichosa que hasta que no consigue lo que se propone no para. Esto no es asi en la vida real. C7.

Las relaciones de parejas que se muestran en el cine romántico no se parecen en nada a las que suceden en la vida realy se idealiza a la pareja completamente. C8.

En el cine romántico suelen aparecer personajes idílicos que no existen en realidad. Con frecuencia hacen historias perfectas y modélicas para captar la atención de los oyentes y que se interesen por ello. C10

Los empresarios vinculados a la industria cinematográfica, cineastas y productoras, no han formado parte, de forma directa, de ninguna de las preguntas del guion de las entrevistas. En cambio, los entrevistados se han referido a ellos en distintos sentidos, señalando la necesidad de que los productores tomen conciencia de la importancia de transmitir un modelo adecuado de hombres y mujeres. En el cuestionario sí preguntamos específicamente por las intenciones de cineastas y productoras y los resultados indican que los hombres desconfían más que las mujeres de sus intenciones. Más de la mitad de ellos considera que el cine muestra fundamentalmente lo que le interesa a las cineastas y productoras $(60 \%$ «muchas veces» $\mathrm{O}$ «siempre»). Ninguno opina lo contrario.

Las opiniones se encuentran bastante divididas, tanto en hombres como en mujeres, entre las tres opciones que señalan que el cine obedece a intereses de los empresarios del mundo cinematográfico (tabla 3). Las diferencias por sexo son estadísticamente significativas. 
Tabla 3. El cine como muestra de lo que interesa a los cineastas y productoras

\begin{tabular}{|l|l|l|l|l|l|l|l|}
\hline \multicolumn{2}{|c|}{} & Nunca & Algunas veces & Muchas veces & Siempre & Total \\
\hline \multirow{2}{*}{$\begin{array}{l}\text { E } \\
\text { E }\end{array}$} & H & Valor absoluto & 0 & 20 & 12 & 18 & 50 \\
\cline { 2 - 8 } & $\%$ &, $0 \%$ & $40,0 \%$ & $24,0 \%$ & $36,0 \%$ & $100,0 \%$ \\
\cline { 2 - 8 } O & \multirow{2}{*}{ M } & Valor absoluto & 10 & 71 & 78 & 38 & 197 \\
\cline { 2 - 8 } & $\%$ & $5,1 \%$ & $36,0 \%$ & $39,6 \%$ & $19,3 \%$ & $100,0 \%$ \\
\hline \multirow{2}{*}{ Total } & Valor absoluto & 10 & 91 & 90 & 56 & 247 \\
\cline { 2 - 8 } & $\%$ & $4,0 \%$ & $36,8 \%$ & $36,4 \%$ & $22,7 \%$ & $100,0 \%$ \\
\hline
\end{tabular}

Fuente: elaboración propia.

En relación a los datos de la tabla 3, varios expertos afirman que, partiendo de la base de que los estereotipos de género han variado muy poco a lo largo de los tiempos, esto se produce porque el director o la directora de esa película tienen que ser muy atrevidos para romper el tabú de lo que se viene vendiendo. En el cuestionario se planteaba una posible vía para revertir esta situación: un mayor control de los contenidos cinematográficos para evitar la transmisión de ideologías dañinas. Si bien las tres cuartas partes están a favor de que se intensifique el control, una cuarta parte, -más frecuente para los hombres con un 36\% frente al 22\% de las mujeres- considera que los contenidos no se deberían controlar más para evitar la transmisión de ideologías no recomendables.

Tabla 4. Grado de acuerdo con controlar los contenidos del cine para evitar que se transmitan ideologías dañinas

\begin{tabular}{|l|l|l|r|r|r|r|r|}
\hline \multicolumn{2}{|c|}{} & Totalmente en desacuerdo & En desacuerdo & De acuerdo & Totalmente de acuerdo & Total \\
\hline $\mathrm{S}$ & $\mathrm{H}$ & Valor absoluto & 2 & 18 & 20 & 10 & 50 \\
\cline { 2 - 8 } $\mathrm{E}$ & & $\%$ & $4,0 \%$ & $36,0 \%$ & $40,0 \%$ & $20,0 \%$ & $100,0 \%$ \\
\cline { 2 - 8 } $\mathrm{X}$ & \multirow{2}{*}{$\mathrm{M}$} & Valor absoluto & 6 & 44 & 98 & 51 & 199 \\
\cline { 2 - 9 } & $\%$ & $3,0 \%$ & $22,1 \%$ & $49,2 \%$ & $25,6 \%$ & $100,0 \%$ \\
\hline \multirow{2}{*}{ Total } & Valor absoluto & 8 & 62 & 118 & 61 & 249 \\
\cline { 2 - 9 } & $\%$ & $3,2 \%$ & $24,9 \%$ & $47,4 \%$ & $24,5 \%$ & $100,0 \%$ \\
\hline
\end{tabular}

Fuente: elaboración propia.

En línea con estas cuestiones, preguntamos también por la consideración del cine como manipulador de las percepciones. La tendencia mayoritaria es señalar la existencia de esa manipulación y de nuevo se aprecia una mayor rotundidad en los hombres que en las mujeres, estas últimas con unas opiniones más moderadas.

Tabla 5. El cine como manipulador de percepciones

\begin{tabular}{|l|l|l|l|l|l|l|l|}
\hline \multicolumn{2}{|c|}{} & Nunca & Algunas veces & Muchas veces & Siempre & Total \\
\hline $\mathrm{S}$ & $\mathrm{H}$ & Valor absoluto & 1 & 18 & 28 & 3 & 50 \\
\cline { 2 - 8 } $\mathrm{E}$ & $\%$ & $2,0 \%$ & $36,0 \%$ & $56,0 \%$ & $6,0 \%$ & $100,0 \%$ \\
\cline { 2 - 8 } $\mathrm{X}$ & \multirow{2}{*}{$\mathrm{O}$} & Valor absoluto & 12 & 95 & 81 & 9 & 197 \\
\cline { 2 - 8 } & $\%$ & $6,1 \%$ & $48,2 \%$ & $41,1 \%$ & $4,6 \%$ & $100,0 \%$ \\
\hline \multirow{2}{*}{ Total } & Valor absoluto & 13 & 113 & 109 & 12 & 247 \\
\cline { 2 - 7 } & $\%$ & $5,3 \%$ & $45,7 \%$ & $44,1 \%$ & $4,9 \%$ & $100,0 \%$ \\
\hline
\end{tabular}

Los universitarios se posicionaron claramente a favor de que el cine contribuya a transmitir ideologías y valores socialmente apropiados, con más mujeres que hombres que creen que esto siempre debería ocurrir: casi la tercera parte de ellas frente a un 16\% de ellos. Un minoritario $10 \%$ no lo consi- 
dera una tarea del cine. Los expertos también van en esta línea, pero han identificado numerosos escollos de diversa índole para que esto ocurra, entre ellos la importancia del «cine comercial» que frecuentemente está cargado de estereotipos sexistas.

En base a los datos de la tabla 6 se puede afirmar que los estudiantes universitarios se decantan mayoritariamente por el acuerdo con que el cine esté al servicio de la sociedad. Las tres cuartas partes de la muestra así lo atestiguan, tanto para hombres como para mujeres. Un $60,7 \%$ se muestra de acuerdo un $14,6 \%$ se declara muy de acuerdo, mientras un $24,7 \%$ muestra su desacuerdo con esta manifestación.

Tabla 6. Grado de acuerdo con que el cine tendría que estar al servicio de la sociedad

\begin{tabular}{|l|l|l|l|l|l|l|l|}
\hline \multicolumn{2}{|c|}{} & Totalmente en desacuerdo & En desacuerdo & De acuerdo & Totalmente de acuerdo & Total \\
\hline \multirow{2}{*}{$\begin{array}{l}\mathrm{S} \\
\mathrm{E}\end{array}$} & $\mathrm{H}$ & Valor absoluto & 1 & 13 & 25 & 11 & 50 \\
\cline { 2 - 8 } $\mathrm{X}$ & $\%$ & $2,0 \%$ & $26,0 \%$ & $50,0 \%$ & $22,0 \%$ & $100,0 \%$ \\
\cline { 2 - 8 } $\mathrm{O}$ & $\mathrm{M}$ & Valor absoluto & 2 & 45 & 125 & 25 & 197 \\
\cline { 2 - 8 } & $\%$ & $1,0 \%$ & $22,8 \%$ & $63,5 \%$ & $12,7 \%$ & $100,0 \%$ \\
\hline \multirow{2}{*}{ Total } & Valor absoluto & 3 & 58 & 150 & 36 & 247 \\
\cline { 2 - 8 } & $\%$ & $1,2 \%$ & $23,5 \%$ & $60,7 \%$ & $14,6 \%$ & $100,0 \%$ \\
\hline
\end{tabular}

Fuente: elaboración propia.

\section{Influencia del cine en el comportamiento de niños y jóvenes}

Los expertos, al ser preguntados por las repercusiones en niños y jóvenes, sentencian que su influencia es clara, pero en la línea de otros formatos culturales. Las entrevistas también aluden al papel del cine como agente socializador o aún más, se le da una capacidad de influencia superior a la de la educación.

El primer ítem del cuestionario abordaba la influencia del cine en la socialización de niños y jóvenes. La casi totalidad de la muestra, excepto un sujeto, mantiene que el cine es un instrumento divulgador de valores que influye en la educación y socialización de niños/as y jóvenes. El análisis cualitativo concluye que la capacidad de influencia del cine no solo afecta a niños y jóvenes, sino a la sociedad en general. Más concretamente, la influencia del cine romántico en sus espectadores tendría diferente alcance en función de tres variables: género, formación de espectadores y edad. Aunque se considera que afecta a ambos géneros, no lo hace por igual, siendo más importante su alcance para las mujeres, ya que un $63,3 \%$ de las mujeres se siente identificada con personajes del cine frente a un $42 \%$ de los hombres.

Si hay un ítem con un reparto más equitativo en cuanto a grados de acuerdo, es el recogido en la tabla número 7 que muestra la opinión de los estudiantes sobre si las imágenes de género mostradas en el cine romántico influyen en las relaciones reales de sus espectadores. El 48,4\% de los encuestados no considera que el cine influya en las relaciones de los espectadores, mientras que para el 51,6\% sí se produce dicha influencia. Las mujeres muestran un grado de acuerdo ligeramente mayor a los hombres, pero los datos son muy similares en función del sexo. 
Tabla 7. Grado de acuerdo con que las imágenes de hombres y mujeres mostradas en el cine romántico influyen en las relaciones reales de los espectadores/as

\begin{tabular}{|l|l|l|r|r|r|r|r|}
\hline \multicolumn{2}{|c|}{} & Totalmente en desacuerdo & En desacuerdo & De acuerdo & Totalmente de acuerdo & Total \\
\hline $\mathrm{S}$ & $\mathrm{H}$ & Valor absoluto & 2 & 24 & 21 & 3 & 50 \\
\cline { 2 - 8 } $\mathrm{E}$ & & $\%$ & $4,0 \%$ & $48,0 \%$ & $42,0 \%$ & $6,0 \%$ & $100,0 \%$ \\
\cline { 2 - 8 } $\mathrm{X}$ & $\mathrm{M}$ & Valor absoluto & 11 & 82 & 96 & 7 & 196 \\
\cline { 2 - 9 } & & & $4,6 \%$ & $41,8 \%$ & $49,0 \%$ & $3,6 \%$ & $100,0 \%$ \\
\hline \multirow{2}{*}{ Total } & Valor absoluto & 13 & 106 & 117 & 10 & 246 \\
\cline { 2 - 9 } & $\%$ & $5,3 \%$ & $43,1 \%$ & $47,6 \%$ & $4,1 \%$ & $100,0 \%$ \\
\hline
\end{tabular}

Fuente: elaboración propia.

Las entrevistas, en términos generales, identifican una ligera diferencia a favor de que las películas románticas tienen un perfil de población con ciertos elementos identificadores, aunque no sean excluyentes ni estén presentes siempre. Mientras para algunos entrevistados está claro que el cine romántico se dirige a un público femenino, otros lo ponen en duda.

La encuesta refleja que no hay diferencias destacables en la opinión de hombres y mujeres al determinar si las películas de género romántico están concebidas para un determinado público. Un $58 \%$ de la muestra está de acuerdo frente a un $42 \%$ que no lo está. Si se presta atención a las posiciones más extremas (totalmente de acuerdo y totalmente en desacuerdo) tampoco hay grandes variaciones. Por tanto, hay una ligera diferencia a favor de que estas películas tienen un perfil concreto de población, pero no se puede desprender, según los datos cuantitativos, que el cine romántico esté enfocado a un determinado público. Las diferencias en los datos son muy similares para los hombres y para las mujeres.

Tabla 8. Grado de acuerdo con que las películas de género romántico están concebidas para un público determinado

\begin{tabular}{|c|c|c|c|c|c|c|c|}
\hline & Totalmente en desacuerdo & En desacuerdo & De acuerdo & Totalmente de acuerdo & Total \\
\hline \multirow{2}{*}{$\begin{array}{l}\mathrm{S} \\
\mathrm{E}\end{array}$} & \multirow[t]{2}{*}{$\mathrm{H}$} & Valor absoluto & 8 & 12 & 22 & 8 & 50 \\
\hline & & $\%$ & $16,0 \%$ & $24,0 \%$ & $44,0 \%$ & $16,0 \%$ & $100,0 \%$ \\
\hline $\mathrm{X}$ & \multirow[t]{2}{*}{$\mathrm{M}$} & Valor absoluto & 14 & 71 & 91 & 22 & 198 \\
\hline $\mathrm{O}$ & & $\%$ & $7,1 \%$ & $35,9 \%$ & $46,0 \%$ & $11,1 \%$ & $100,0 \%$ \\
\hline \multirow{2}{*}{\multicolumn{2}{|c|}{ Total }} & Valor absoluto & 22 & 83 & 113 & 30 & 248 \\
\hline & & $\%$ & $8,9 \%$ & $33,5 \%$ & $45,6 \%$ & $12,1 \%$ & $100,0 \%$ \\
\hline
\end{tabular}

Fuente: elaboración propia

Paralelamente, en las respuestas abiertas, encontramos algunas referencias concretas a que este tipo de cine está dirigido a mujeres.

No son muy reales hablan de relaciones irreales y utópicas y que siempre terminan juntos encontrando a su media naranja sin embargo creo que gustan a la mayoría porque son ilusorias y nos bacen pensar sobre todo a las mujeres que pueden ser real o que podría sucedernos algo así. C53

Creo que el cine sigue mostrando la realidad social: las mujeres buscan a su príncipe azuly se consuelan viendo películas románticas, sin embargo, la sociedad, comienza a avanzar y la liberalización de la mujer se hace más patente cada vez, por lo que creo que esta debería representarse más fielmente. C100

Por otra parte, los datos de la encuesta apuntan a claras diferencias entre las películas de género romántico consumidas por ellos y por ellas. En primer lugar, en el número. De las 20 películas propuestas (coincidentes con los títulos de nuestro análisis), las universitarias habían visto una media de 
10 films, mientras sus compañeros referían 4 de promedio. Además, las películas más populares entre las mujeres eran las más clásicas dentro del género, destacando por encima de todas el Diario de Noa, que es el que cuenta con más mitos: el mito del Amor Romántico, el Amor como algo mágico e Incontrolable y el de la Media naranja. Los hombres, en cambio, se decantaban más por la comedia, con una abrumadora mayoría de los que habían sido espectadores de American Pie 2, que no refleja ninguno de los tres mitos citados.

Por último, a partir de las fichas analíticas de las relaciones de pareja mostradas en los 20 films seleccionados, en 9 de ellos conviven el modelo Tradicional con el Alternativo; en 2 películas solo se muestra el modelo Tradicional y en otras 9 el modelo predominante es el Alternativo. Es preciso matizar que no se trata de modelos puros, es decir, que cada película no tiene que contener necesariamente todas las variables que se han considerado para cada modelo, aunque sí la mayoría de ellas. Estos datos contrastan con la percepción de los estudiantes universitarios que apunta a un predominio del Modelo Tradicional, pero van en la línea de opinión de los expertos que constatan que se han producido cambios en la dirección de mostrar relaciones más igualitarias y menos estereotipadas.

\section{DisCUSIÓN DE RESULTADOS}

La muestra de estudiantes universitarios que ha participado en la encuesta puede haber determinado en parte los resultados obtenidos. Su pertenencia a titulaciones vinculadas al ámbito educativo y de la comunicación puede haber incrementado su sensibilidad y actitud crítica ante determinadas cuestiones. Sería conveniente continuar esta línea de investigación con otras titulaciones, para verificar si existen diferencias significativas con respecto a los datos obtenidos.

El cine, al igual que otros medios de comunicación de masas, ha sido durante décadas una herramienta perpetuadora de estereotipos (Loscertales, 1999; Gordillo, 2007). Más recientemente, parece que encontramos una cierta evolución hacia posturas más igualitarias. A pesar de ella, los medios de comunicación masiva tienden a repetir y masificar los estereotipos sociales. El cine y la televisión, y más recientemente Internet, son quizá los medios más influyentes en la masificación de información estereotipada.

Una de las razones por las cuales el estereotipo suele ser peligroso es porque esconde en su elaboración una idea fija que se niega a ser analizada o contrastada con la realidad (Mazzara, 1999). Si los esquemas mentales no son revisados, analizados o criticados, tienden a convertirse en modos de ser que llevan a la ignorancia, el fanatismo y a acciones irracionales.

Cuando suponemos que los varones son de una determinada manera y, del mismo modo, tratan a las mujeres suponiendo que son de otra forma definida, se niega la evidencia que muestra que las personas son diferentes, individuos que pueden cambiar, modificar conductas, establecer nuevos patrones de convivencia, transformar su historia personal, etc., y que no están predeterminados en cuanto actitudes, pensamientos y acciones, por su sexo. Un estereotipo tiende a inmovilizar; deja a los individuos en un patrón fijo que no se modifica. Tratar a las personas en base a prejuicios y estereotipos, simplemente es el peor modo de vincularse con otros. Podemos afirmar, al igual que lo hace Aguilar (2011), que los estereotipos forman prejuicios que llevados a la práctica fomentan el error, la ignorancia y la intolerancia en todas sus formas.

\section{CONCLUSIONES}

El apellido «social» ha estado muy presente en el acercamiento al cine que ha realizado el artículo. Como medio de comunicación, el cine ha ido evolucionando, aunque este discurrir no ha sido lineal. 
Desde sus inicios, el cine ha estado muy ligado al contexto social en que se produce y consume; en esta línea, el artículo ha analizado el género cinematográfico romántico para determinar si lo que proyecta se corresponde con una perspectiva de género conservadora o igualitaria, y las influencias que tiene en sus espectadores.

Además de suponer un mecanismo de evasión de la realidad y de atesorar los intereses de una industria cultural, el cine se ha mostrado como un medio influyente en la sociedad en general y en sus espectadores en particular. Los datos apuntan a que tiene potencial en la manipulación de las percepciones, y este dato tiene importantes consecuencias en cuanto a las repercusiones de los contenidos, diálogos e imágenes que muestra. Los estudiantes universitarios se inclinan a favor de que el cine esté al servicio de la sociedad. Casi la mitad de la muestra considera que influye incluso en las relaciones reales de los espectadores.

Las diferencias entre hombres y mujeres no han sido significativas en la mayoría de ítems de la encuesta. En cambio, en el análisis fílmico de las 20 películas de corte romántico más taquilleras de la primera década del Siglo XXI, existen notables diferencias en cuanto a la frecuencia de su consumo (ellas habían visto una media de 10 films frente a las 4 vistas por ellos) y en cuanto al tipo de producto fílmico que consumen entre sexos (entre las mujeres la película más vista fue el Diario de Noa, y entre los hombres American Pie 2).

Esta selección ha evidenciado que el cine romántico tiene diferencias internas, encontrando una cierta diversidad en sus argumentos y en sus reflejos de valores y contravalores. Mientras unas películas se ajustan a los cánones de género romántico como arquetipo, otras tratan las relaciones de pareja contraponiendo numerosos modelos de relación, mostrando diferencias entre las relaciones amorosas de dos generaciones o modelos basados en la igualdad de géneros. Esto se traduce en films que apuestan más por un modelo Tradicional de relaciones de pareja, otros que reflejan un modelo Alternativo y casi la mitad de la muestra que muestra ambos.

Por otra parte, no existe consenso a la hora de determinar si el cine de tipo romántico se dirige a un determinado público. Parece que el género, la edad y la formación podrían tener cierta incidencia en algunos casos, pero no pueden ser consideradas como variables determinantes. Más allá de elementos sociodemográficos, la preferencia por el género romántico (no muy bien valorado por los expertos) dependería más de gustos y preferencias personales.

Existe una idea generalizada de que el cine ha evolucionado, al igual que lo ha hecho la sociedad, hacia mayores cotas de igualdad. A pesar de ello, existen aún múltiples muestras de estereotipos de género, mitos de relaciones de pareja y modelos relacionales muy conservadores que son mostrados en films que ven millones de espectadores. Se hace necesario seguir avanzando para que el cine refleje relaciones de pareja igualitarias, deconstruya roles y estereotipos de género y, en definitiva, contribuya a construir una sociedad menos patriarcal.

Si el cine es divulgador de valores que influyen en los espectadores, refleja una realidad social a veces alejada de la realidad y tiene poder para manipular las percepciones de los espectadores, es un medio de comunicación que tiene un gran potencial. Estas características pueden ser aprovechadas, entre otras cosas, para reducir los estereotipos de género y propugnar relaciones de pareja más igualitarias entre niños y jóvenes que, dentro de sus agentes socializadores, cuentan con los medios de comunicación, entre los que se encuentra el cine. 


\section{BIBLIOGRAFÍA}

Aguilar, J. E. (2011). Prejuicios, estereotipos y discriminación. México: Network de Psicología Organizacional: Asociación Oaxaqueña de Psicología AC Oaxaca. Recuperado de: https://es.scribd.com/document/73618437/prejuicio-estereotipo-discriminacion

Almacellas, M. A. (2004). Educar con el cine. Madrid: Ediciones Internacionales Universitarias.

Alonso, M. ${ }^{a}$ L. y Pereira, M. ${ }^{a}$ C. (2000). El cine como medio recurso para la educación en valores. Un enfoque teórico y tecnológico. Pedagogía Social. Revista Interuniversitaria 5, 2. época, 127-147.

Badiou, A. (2004). El cine como experimentación filosófica. En G. Yoel (comp.), Pensar el cine 1: imagen, ética y filosofía. Buenos Aires: Manantial.

Benet, J. (2004). La cultura del cine. Introducción a la historia y la estética del cine. Barcelona: Ediciones Paidós Ibérica.

Blasco, J. S. y Bueno, F. C. (2015). Género sicalíptico y crítica social: La Corte de Faraón en el cine. Opción, 31(1), 149-163.

Blasco, P. G., Moreto, G., Blasco, M. G., Levites, M. R. y Janaudis, M. A. (2015). Education through Movies: Improving Teaching Skills and Fostering Reflection among Students and Teachers. Journal for Learning Through the Arts, 11(1). Recuperado de: http://escholarship.org/uc/item/2dt7s0zk

Caballo, L. R. (2014). Cine y problemas de pareja. El road movie/Films and relationship problems. The road movie. Arteterapia, 9, 289-308. doi: http://dx.doi.org/10.5209/rev_ARTE.2014.v9.47497

Caparrós, J. M. (2007). Guía del espectador de cine. Madrid: Alianza Editorial.

Castro, M. (2006). El Cine como Instrumento de Socialización. Revista de Filosofía A Parte Rei, 47, 1-6.

Charkow, W. B. y Nelson, E. S. (2000). Relationship dependency, dating violence and scripts of female. Journal of College Counselling, 3(1), 12-17.

Escámez, J. y Gil, R. (2001). La educación en la responsabilidad. Barcelona: Paidós.

Gómez, C. M. (2017). Cine y Salud: Una estrategia audiovisual en la educación saludable con adolescentes. Forum Aragón, 20, 15-19.

González Galiana, R. (1999). La construcción de estereotipos andaluces por los medios. Comunicar, 12, 101-106.

González, F. (1996). Temas transversales y educación en valores. Madrid: Alauda.

Gordillo, I. (2007). El diálogo intercultural en el cine español contemporáneo: entre el estereotipo y el etnocentrismo. Revista Internacional de Comunicación Audiovisual, Publicidad y Literatura, 1(4), 207-222.

Gutiérrez, D. (2009) Debates en torno a las identidades Volumen 122 de Documentos de investigación. México: El Colegio mexiquense.

Higgins, J. y Dermer, S. (2001). The use of film in marriage and family education. Counselor Education and Supervision, 40(3), 182-192.

Jaimes, L. R. (2016). El cine: una estrategia didáctica en el desarrollo de la inteligencia ética. Encuentro Educacional, 22(3), 432-446

Kohan, S. (2006). Biblioterapia y cineterapia. Barcelona: Editorial Debolsillo.

Leigh, J. (2002). The cinema of Ken Loach: art in the service of the people. London-New York: Wallflower.

López, E. (2008). Pautas de la observación y análisis del sexismo. Los materiales educativos. Logroño: Universidad de la Rioja.

Loscertales, F. (1999). Estereotipos y valores de los profesores en el cine. Comunicar, 12, 37-45.

Lozano, D. F., Barragán, J. N., Guerra, S. A., Villalpando Cadena, P., Treviño Ayala, M. E. y Pureco de León, J. L. (2012). Factores mercadológicos utilizados por las organizaciones de producción 
cinematográfica mexicanas (OPCM) y su impacto en los ingresos en taquilla: caso de estudio área metropolitana de Nuevo León. Innovaciones de negocios, 17(9), 57-84. Recuperado de: http://www.web.facpya.uanl.mx/rev in/Revistas/9.1/A4.pdf

Lozano, D. Barragán, J. y Guerra, S. (2009). El cine: El negocio de la cultura. UANL, Innovaciones de Negocios, 6(2), 207- 224.

Mangot, A. y Vasantmeghna, S. (2017). Cinema: A multimodal and integrative medium for education and therapy. Annals of Indian Psychiatry, 1 (1), 51-53. doi: https://doi.org/10.4103/aip.aip_13_1710.4103/aip.aip_13_17

Martínez, A., \& Merlino, A. (2006). Discurso y socialización en producciones cinematográficas infantiles. Comunicar, 26, 125-130.

Mayne, J. (1993). Cinema and Spectatorship. London: Routledge.

Mazzara, B. M. (1999). Estereotipos y prejuicios. Madrid: Acento.

McCann, E. y Huntley-Moore, S. (2016). Madness in the movies: An evaluation of the use of cinema to explore mental health issues in nurse education. Nurse education in practice, 21, 37-43. doi: https://doi.org/10.1016/i.nepr.2016.09.009

McConnell, C. (1997). Economía, principios, problemas y politicas. Bogotá: McGraw Hill Interamericana.

McKee, R. (2011). El guión. Madrid: Albaminus

Molina, R. B. (2016). Género y relaciones de pareja: cineterapia y biblioterapia. Revista Vinculando. Recuperado de: http://vinculando.org/psicologia psicoterapia/genero-relaciones-parejacineterapia-biblioterapia.html

Montiel, A. (1999). Teorías del cine. El reino de las sombras. España: Montesinos.

Morales, B. (2015). Roles y estereotipos de género en el cine romántico de la última década. Perspectivas educativas. (Tesis doctoral no publicada). Universidad de Salamanca, España.

Ojeda, S. L. (2016). La política va al cine. Revista Mexicana de Análisis Político y Administración Pública, 5(2), 198-200.

Porto, L. (2010). Socialización de la infancia en películas de Disney/Pixar y Dreamworks/PDI. Análisis de modelos sociales en la animación. Prisma Social, 4, 1-20.

Puleo, A. (2005). El patriarcado: ¿una organización social superada. Temas para el debate, 133, 39-42.

Ruiz, R. (2013). Poéticas del cine. Santiago de Chile: Ediciones Universidad Diego Portales.

Sabeckis, C. (2013). El séptimo arte en la era de la revolución tecnológica. Cuadernos del Centro de Estudios en Diseño y Comunicación. Ensayos, 45, 53-64.

San Román, G. (2010). Metamorfosis de la lectura. Madrid: Anagrama.

Sell, L., Martínez-Pecino, R. y Loscertales, F. (2014). El cine como herramienta educativa para abordar la violencia en las aulas. Píxel-Bit. Revista de Medios y Educación, 45, 111-124. doi: https://doi.org/10.12795/pixelbit.2014.i45.08

Stadler, J. (2017). Seeing with green eyes: Tasmanian landscape cinema and the ecological gaze. Senses of Cinema, 65. Recuperado de: http://sensesofcinema.com/2012/tasmania-and-thecinema/seeing-with-green-eyes-tasmanian-landscape-cinema-and-the-ecological-gaze/

Tabernero, C. (2016). Terapias de cine: 50 películas básicas entorno a la medicina. Barcelona: Editorial UOC.

Téllez, O. (2005). Arte y sus consumos. En la memoria del Encuentro de promotores y gestores culturales. Zacatecas: Consejo Nacional para la Cultura y las Artes y el Gobierno de Zacatecas.

Zallo, R. (1992). El mercado de la cultura. Estructura económica y política de la comunicación. Donostia: Gakoa Liburuak. 